American J. of Engineering and Applied Sciences 2 (1): 120-126, 2009

ISSN 1941-7020

(C) 2009 Science Publications

\title{
Heating Effects on Structural and Electrical Properties of Polyetherimide
}

\author{
${ }^{1}$ Nissaf Mzabi, ${ }^{1}$ Hichem Smaoui, ${ }^{1}$ Hajer Guermazi, ${ }^{1}$ Youssef Mlik, \\ ${ }^{2}$ Serge Agnel and ${ }^{2}$ Alain Toureille \\ ${ }^{1}$ Unity of Physics of Insulating and Semi-Insulating Materials, \\ Preparatory Institute for Engineer Studies of Sfax, 1172, 3018 Sfax, Tunisia \\ ${ }^{2}$ LEM, University Montpellier II, Place Eugène Bataillon, 34095 Montpellier, France
}

\begin{abstract}
Problem statement: Polyetherimide (PEI) has several uses such as electrical insulation. It can undergo different constraints like heat or high voltage which influence its performances as insulator. In this study, the effects of heating on structural and electrical properties of polyetherimide (Ultem 1000) are studied. Approach: PEI samples were heated at different temperatures below the glass transition temperature $\left(175,190\right.$ and $\left.205^{\circ} \mathrm{C}\right)$. Different complementary techniques were used to investigate structural alterations and dielectric relaxations. These are infrared (IR) spectroscopy, Differential Scanning Calorimetry (DSC), Thermally Stimulated Depolarisation Current (TSDC) technique and Dielectric Spectroscopy (DS). Results: Physical ageing was revealed in heated samples by DSC analysis. DS and TSDC results have shown that dipolar relaxations are affected by heating. The amount of relaxing dipoles decreases when the material is heated at $190^{\circ} \mathrm{C}$. Conclusion/Recommendations: The heating of polyetherimide at $190^{\circ} \mathrm{C}$ leads to a stabilisation of charges in deeper energetic levels which influences the insulating character of the material.
\end{abstract}

Key words: PEI, temperature, physical ageing, dielectric relaxations

\section{INTRODUCTION}

Polyetherimide (PEI) is suitable for industrial applications, including electrical insulation ${ }^{[1-3]}$. Its properties are influenced by environmental parameters such as radiations, pressure, temperature. Studies on the effects of these parameters could give information on material reliability. Numerous investigations on PEI properties have been made by researchers ${ }^{[1-9]}$. The relaxational behaviour of this material is one of the researched topics. Belana et al. ${ }^{[5]}$ have shown different relaxations in PEI related to dipole motions, which are identified as $\gamma, \beta$ and $\alpha$ relaxations. The influence of gamma irradiation on charge relaxations in PEI has been presented in a previous research ${ }^{[7]}$. A relationship was found between structural changes and dipolar relaxations.

The present research deals with a post-heating study on polyetherimide (Ultem 1000). This study focuses on the evolution of structure and dielectric relaxations in PEI heated at different temperatures below Tg.

Infrared spectroscopy and differential scanning calorimetry are used to examine structural alterations. Measurements are performed by means of TSDC technique and dielectric spectroscopy to investigate charge relaxations. Results obtained by different techniques are discussed, emphasizing the heating effect.

\section{MATERIALS AND METHODS}

The polyetherimide (Ultem 1000) is an amorphous thermoplastic resin with a high glass transition temperature $\mathrm{Tg}$ of around $220^{\circ} \mathrm{C}$. Its chemical structure is represented schematically on Fig. 1.

Samples used in this research are films of $125 \mu \mathrm{m}$ thickness, supplied by General Electric Corporation. Heating was carried out using an 'ULE 500 Memmert' oven, at different temperatures below $\operatorname{Tg}(175,190$ and $205^{\circ} \mathrm{C}$ ) during $24 \mathrm{~h}$.

Differential scanning calorimetry: Differential Scanning Calorimetry (DSC) is used to investigate the thermal transitions in the polymer, for instance, it allows to determine the glass transition temperature. Moreover, the enthalpy relaxation due to physical ageing can be determined from DSC measurements ${ }^{[8]}$.

Differential scanning calorimetry measurements were carried out on PEI samples using a DSC 131

Corresponding Author: Nissaf Mzabi, Unity of Physics of Insulating and Semi-Insulating Materials, Preparatory Institute for Engineer Studies of Sfax, 1172, 3018 Sfax, Tunisia Tel: +21674241403 Fax: +21674246347 
SETARAM instrument, at $10^{\circ} \mathrm{C} \mathrm{min}^{-1}$ heating rate. Samples have a weight of about $11.7 \mathrm{mg}$.

Infrared spectroscopy: Infrared spectroscopy analysis is a well known means for characterizing chemical structure. FTIR-ATR measurements on PEI samples were recorded using EXUINOX 55 spectrometer, in the $4000-550 \mathrm{~cm}^{-1}$ spectral region. The spectrometer was operated at a resolution of $4 \mathrm{~cm}^{-1}$.

Thermally stimulated depolarisation current technique: The Thermally Stimulated Depolarisation Current (TSDC) technique is based on measuring a current due to the depolarization of the sample by thermal activation. The charged sample is placed in an 'Eurotherm' oven which is programmed to rise linearly in temperature. It is short-circuited through an electrometer (Keithley 486). TSDC measurements provide information on relaxation processes occurring in the material. TSDC spectra present several peaks or bands indicating that several processes are operative. Two of these processes are the reorientation of permanent dipoles and the release of charges from traps.

In the present research, TSDC measurements were performed on PEI samples of $(4.4 \times 4.4) \mathrm{cm}^{2}$ dimensions. Aluminium electrodes of $1.6 \mathrm{~cm}$ in diameter were deposited under vacuum on both sides of each sample.

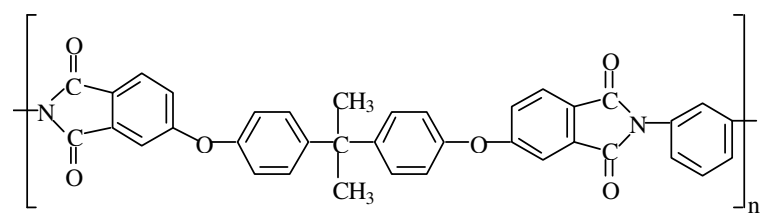

Fig. 1: Schematic representation of the chemical structure of polyetherimide (Ultem 1000) ${ }^{[2]}$

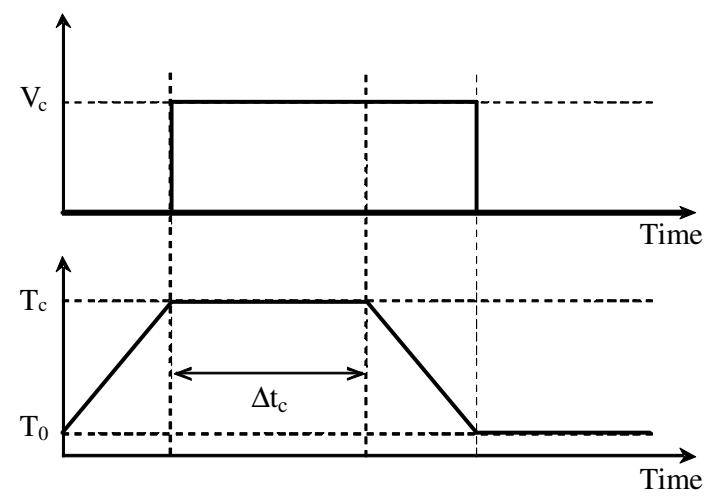

Fig. 2: Process of electrical conditioning of samples
Before measurements, samples were submitted to an electrical field $\mathrm{E}_{\mathrm{c}}=20 \mathrm{kV} \mathrm{mm} \mathrm{m}^{-1}$ at a temperature $\mathrm{T}_{\mathrm{c}}=100^{\circ} \mathrm{C}$ during $\Delta \mathrm{t}_{\mathrm{c}}=5 \mathrm{~h}$, then cooled under field and short-circuited during $1 \mathrm{~h}$. The process of electrical conditioning is shown on Fig. 2. TSDC spectra were recorded at a heating rate of $2^{\circ} \mathrm{C} \mathrm{min}^{-1}$.

Dielectric spectroscopy: Dielectric measurements were performed using a Hewlett Packard 4192A impedance analyser, in the frequency range from $5 \mathrm{~Hz}$ to $12.5 \mathrm{MHz}$, at room temperature. PEI samples are squares around $(1 \times 1) \mathrm{cm}^{2}$. The applied voltage amplitude was $50 \mathrm{mV}$. Before measurements gold electrodes of $3 \mathrm{~mm}$ in diameter were deposited under vacuum on both sides of each sample.

\section{RESULTS}

DSC results: DSC measurements were carried out on the virgin sample and samples heated at different temperatures $\left(175,190\right.$ and $\left.205^{\circ} \mathrm{C}\right)$. The thermograms are given on Fig. 3. The glass transition temperature of the virgin sample is approximately $218^{\circ} \mathrm{C}$.

A remarkable endothermic peak at the glass transition is observed on thermograms of heated samples. This peak associated with the enthalpy relaxation $^{[10]}$ reveals a physical ageing in heated samples.

Figure 3 shows a variation of the endothermic peak area accompanied with a displacement of $\mathrm{Tg}$ to high temperatures. The endothermic peak area is more important at the heating temperature of $190^{\circ} \mathrm{C}$. Therefore the enthalpy relaxation is more important which shows a higher degree of physical ageing.

Infrared results: Infrared spectroscopy measurements were performed on the virgin sample and samples heated at different temperatures $\left(175,190\right.$ and $\left.205^{\circ} \mathrm{C}\right)$.

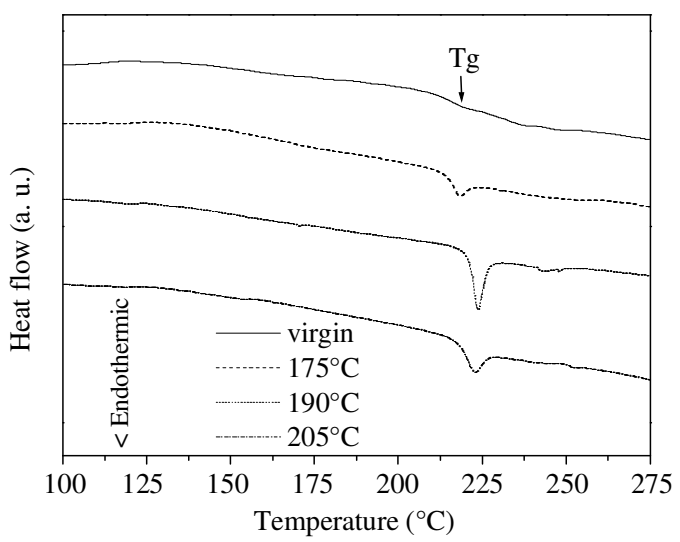

Fig. 3: DSC thermograms of PEI samples 
Am. J. Engg. \& Applied Sci., 2 (1): 120-126, 2009

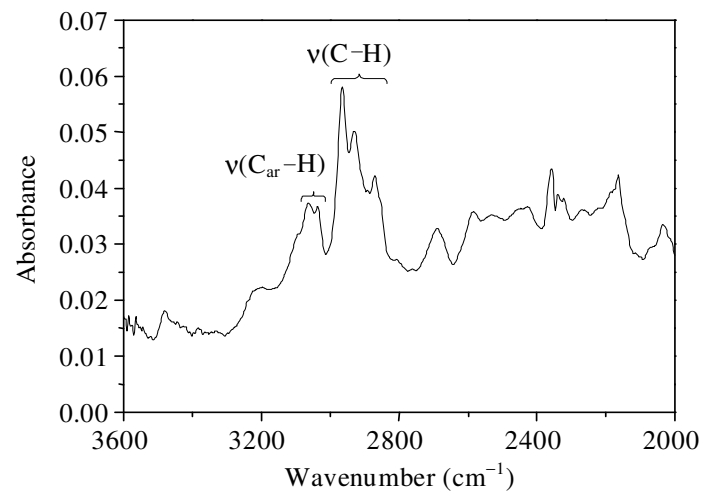

(a)

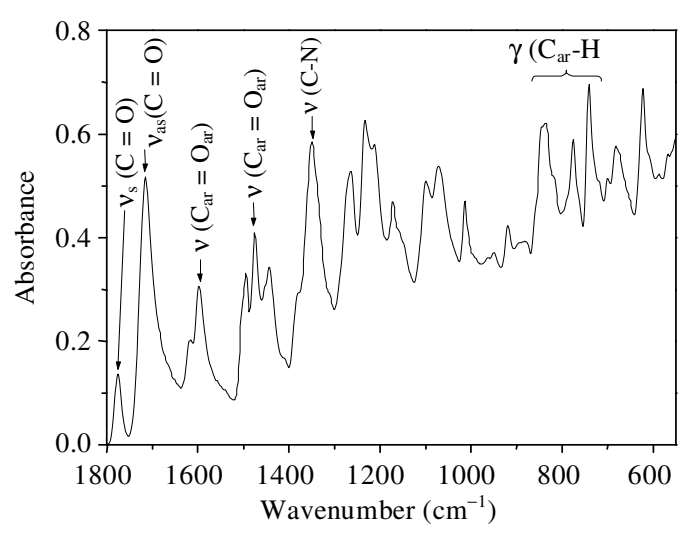

(b)

Fig. 4: Infrared spectrum of the virgin PEI sample in various wavenumber ranges. (a): $3600-2000 \mathrm{~cm}^{-1}$; (b): $1800-550 \mathrm{~cm}^{-1}$

Figure 4 shows the FTIR-ATR spectrum of the virgin sample. The assignments of the main absorption bands, made basing on literature ${ }^{[7,11-14]}$ are shown in Fig. 4.

Infrared spectra of the virgin and heated samples are given on Fig. 5. The intensities of absorption bands are found to be reduced after heating. We notice also a disappearance of the absorption band at $2850 \mathrm{~cm}^{-1}$ assigned to $\mathrm{C}-\mathrm{H}$ vibration, after heating (Fig. 5a).

TSDC results: We have performed TSDC measurements on un-heated sample and samples heated at 175 and $190^{\circ} \mathrm{C}$, submitted to an electrical conditioning $\left(20 \mathrm{kV} \mathrm{mm}^{-1}, 100^{\circ} \mathrm{C}, 5 \mathrm{~h}\right)$. The spectra are shown in Fig. 6.

Each spectrum shows two peaks assigned to $\beta$ dipolar relaxations ${ }^{[5,6]}$. The first one is around $70^{\circ} \mathrm{C}\left(\beta_{2}\right)$ and the second one with a higher intensity appears at about $170^{\circ} \mathrm{C}\left(\beta_{1}\right)$. We notice an important decrease of the $\beta_{1}$ relaxation peak intensity when PEI is heated at $190^{\circ} \mathrm{C}$.

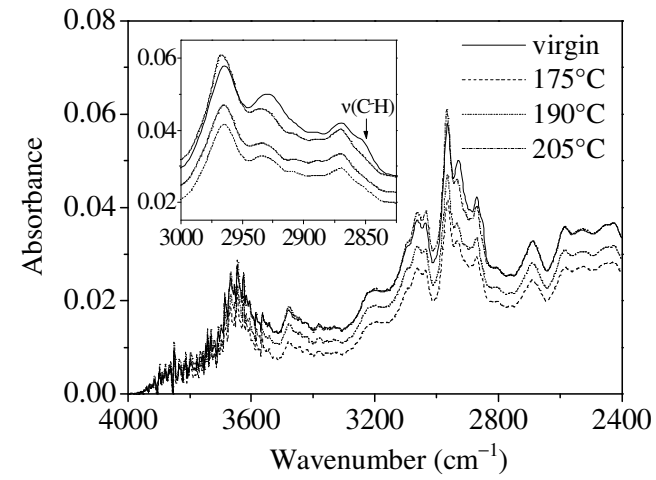

(a)

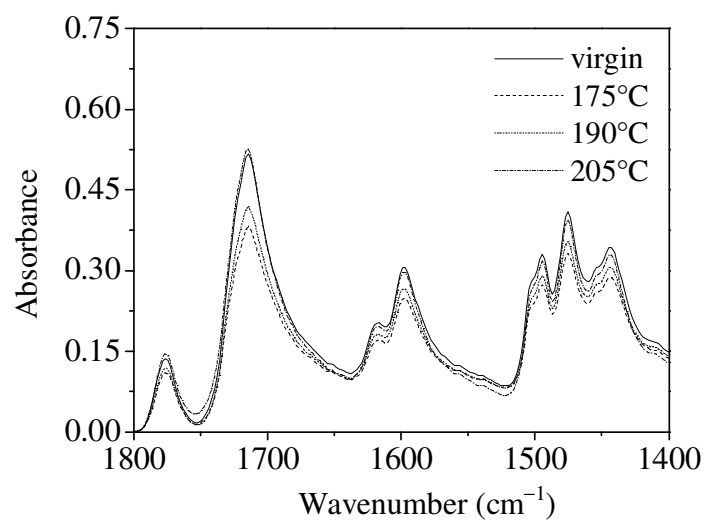

(b)

Fig. 5: Infrared spectra of virgin sample and samples heated at different temperatures in various wavenumber ranges. (a): 4000-2400 $\mathrm{cm}^{-1}$; (b): $1800-1400 \mathrm{~cm}^{-1}$

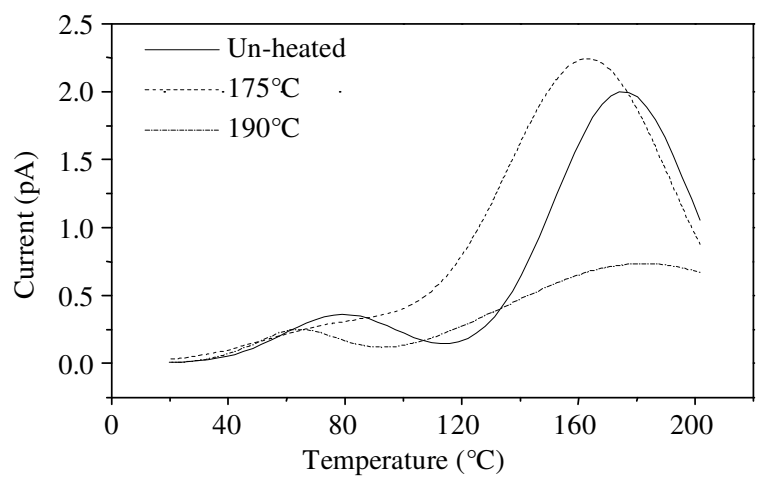

Fig. 6: TSDC spectra of un-heated sample and samples heated at different temperatures

In order to study separately each relaxation, we have separated the relaxation peaks by means of a Gaussian fit decomposition of TSDC spectra. The Gaussian function is given by the following expression: 


$$
\mathrm{I}(\mathrm{T})=\frac{\mathrm{A}}{\Delta \mathrm{T} \sqrt{\pi / 2}} \exp \left(-\left(\frac{\mathrm{T}-\mathrm{T}_{0}}{\Delta \mathrm{T}}\right)^{2}\right)
$$

Where:

$\mathrm{A}=$ The area of current peak

$\Delta \mathrm{T}=$ Its middle-height width and $\mathrm{T}_{0}$ is the peak temperature

Decomposed spectra are represented on Fig. 7. The relaxation peak parameters were calculated and shown in Table 1.

It is clearly observable that peak areas of $\beta_{1}$ and $\beta_{2}$ relaxations increase after heating $\mathrm{PEI}$ at $175^{\circ} \mathrm{C}$. As the peak area is proportional to the amount of dipoles relaxing by thermal activation, the amount of dipoles relaxing during TSDC measurements, is more important in sample heated at $175^{\circ} \mathrm{C}$. On the other hand, the areas of the relaxation peaks decrease when PEI is heated at $190^{\circ} \mathrm{C}$.

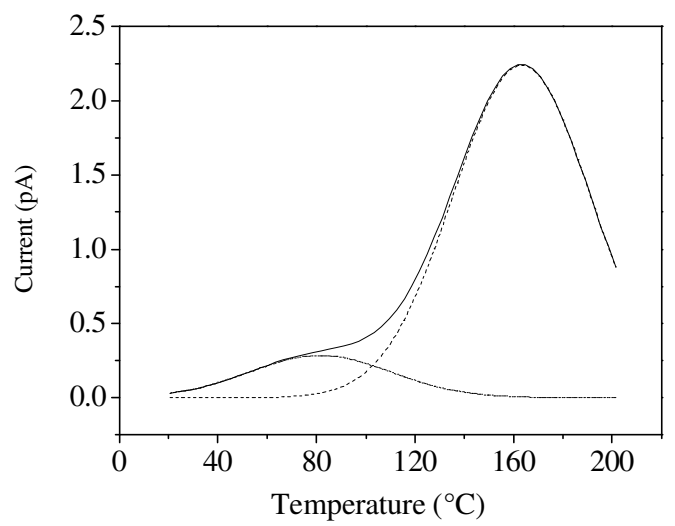

(b)

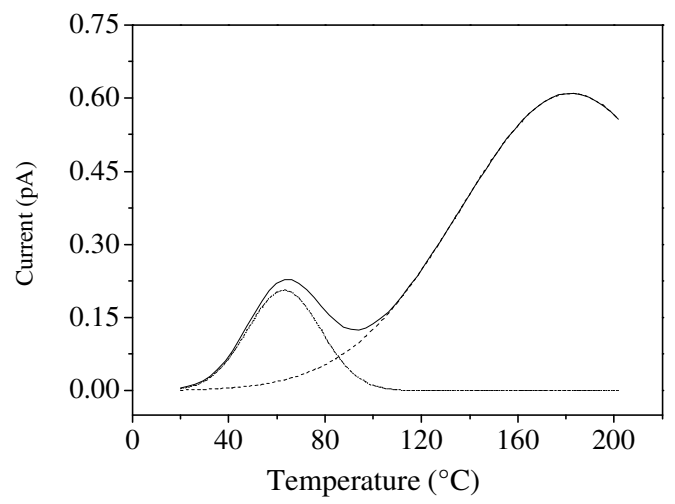

(c)

Fig. 7: Plots obtained by decomposition of TSDC spectra of (a): Un-heated sample and samples heated at temperature ((b) $175^{\circ} \mathrm{C}$ and (c) $\left.190^{\circ} \mathrm{C}\right)$
DS results: Dielectric measurements were performed on un-heated sample and samples heated at 175 and $190^{\circ} \mathrm{C}$. Figure 8 shows the dielectric permittivity $\varepsilon^{\prime}$ and the dielectric loss $\varepsilon$ " as a function of frequency for unheated sample.

The observed decrease in $\varepsilon^{\prime}$ with increasing frequency, reflects dielectric relaxation, then dipoles are not able to change easily orientation with increasing alteration rates of the applied field.

Table 1: Peak parameters of $\beta_{1}$ and $\beta_{2}$ relaxations of un-heated sample and samples heated at 175 and $190^{\circ} \mathrm{C}$

\begin{tabular}{|c|c|c|c|c|}
\hline Relaxation & Sample & $\begin{array}{l}\text { Peak } \\
\text { temperature } \\
\left({ }^{\circ} \mathrm{C}\right)\end{array}$ & $\begin{array}{l}\text { Peak } \\
\text { area } \\
\text { (pA. K) }\end{array}$ & $\begin{array}{l}\text { Middle- } \\
\text { height } \\
\text { width }\left({ }^{\circ} \mathrm{C}\right)\end{array}$ \\
\hline$\overline{\beta_{1} \text { relaxat }}$ & Un-he & 175.35 & 116.61 & 46.46 \\
\hline$\beta_{1}$ relax & Heated at $175^{\circ} \mathrm{C}$ & 163.29 & 157.01 & 55.92 \\
\hline$\beta_{1}$ relaxation & Heated at $190^{\circ} \mathrm{C}$ & 182.09 & 70.64 & 92.43 \\
\hline$\beta_{2}$ relaxation & Un-heated & 79.39 & 18.22 & 46.64 \\
\hline$\beta_{2}$ relaxation & Heated at $175^{\circ} \mathrm{C}$ & 81.50 & 20.55 & 57.78 \\
\hline$\beta_{2}$ relaxation & Heated at $190^{\circ} \mathrm{C}$ & 63.00 & 7.87 & 30.44 \\
\hline
\end{tabular}

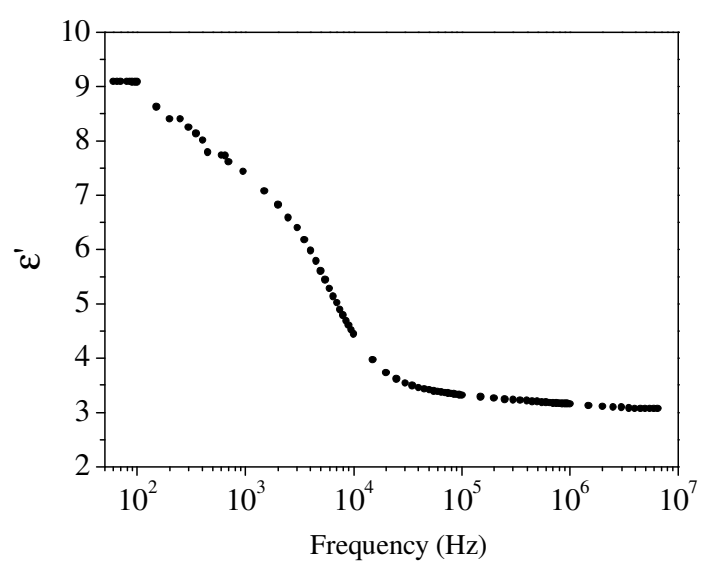

(a)

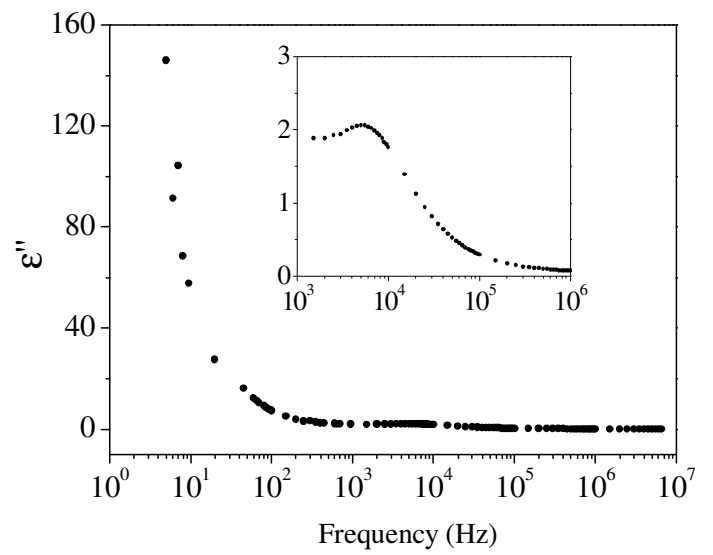

(b)

Fig. 8: Plots of $\varepsilon^{\prime}$ (a) and $\varepsilon^{\prime \prime}$ (b) versus frequency for un-heated sample 
This dipolar relaxation was also detected on $\varepsilon^{\prime \prime}(\mathrm{f})$ plot (Fig. 8b) by a loss peak at around $5 \mathrm{kHz}$. We notice a sharp increase of $\varepsilon^{\prime \prime}$ at low frequencies due to conductive process.

Conduction obscures an eventual interfacial relaxation in permittivity presentation. To overcome this difficulty we have used the electric modulus formalism. An advantage of using the electric modulus to interpret interfacial relaxations, is that variations in the large values of permittivity and conductivity at low frequencies are minimized ${ }^{[18]}$. Complex modulus is defined by:

$$
M^{*}=\frac{1}{\varepsilon^{*}}=\frac{1}{\varepsilon^{\prime}-j \varepsilon^{\prime \prime}}=\frac{\varepsilon^{\prime}}{\varepsilon^{\prime 2}+\varepsilon^{\prime 2}}+j \frac{\varepsilon^{\prime \prime}}{\varepsilon^{\prime 2}+\varepsilon^{\prime 2}}=M^{\prime}+j M^{\prime \prime}
$$

where $\varepsilon^{\prime}$ and $\varepsilon^{\prime \prime}$ are the real and the imaginary parts of complex permittivity $\varepsilon^{*}, M^{\prime}$ and $M^{\prime \prime}$ are the real and the imaginary parts of complex modulus $\mathbf{M}^{*}$.

M" versus frequency plotted on Fig. 9, exhibits a peak at around $82 \mathrm{~Hz}$ which indicates a charge relaxation at the interfaces.

Heating effect: The $\varepsilon^{\prime \prime}$ versus frequency plots are given on Fig. 10 for un-heated and heated samples. We notice that the dipolar relaxation frequency decreases from $5078-4588 \mathrm{~Hz}$ for the heating temperature of $190^{\circ} \mathrm{C}$.

Variations of $\mathrm{M}^{\prime \prime}$ versus $\mathrm{M}^{\prime}$ plots of un-heated and heated samples are given on Fig. 11. Figure 11 shows two depressed semicircles for each sample. The first one corresponds to the interfacial relaxation, while the second semicircle is associated with dipolar relaxation. These semicircles were fitted to Cole-Cole approach according to the Eq. 3 given as follows ${ }^{[18]}$ :

$$
\begin{aligned}
& \left(M^{\prime}-\frac{1}{2}\left(M_{\infty}+M_{s}\right)\right)^{2}+\left(M^{\prime \prime}+\frac{1}{2}\left(M_{\infty}-M_{s}\right) \operatorname{tg} \frac{\alpha \pi}{2}\right)^{2} \\
& =\left(\frac{1}{2}\left(M_{\infty}-M_{s}\right) \sec \frac{\alpha \pi}{2}\right)^{2}
\end{aligned}
$$

where, $\mathrm{M}_{\mathrm{s}}=\frac{1}{\varepsilon_{\mathrm{s}}}$ and $\mathrm{M}_{\infty}=\frac{1}{\varepsilon_{\infty}}, \varepsilon_{\mathrm{s}}$ and $\varepsilon_{\infty}$ denote respectively the relaxed and un-relaxed dielectric permittivities associated with the relaxation process and $\alpha$ is a parameter characterizing the relaxation time distribution. The most significant changes appear on the semicircle associated with dipolar relaxation.

The values of $\alpha, \varepsilon_{\mathrm{s}}, \varepsilon_{\infty}$ and the relaxation strength $\left(\Delta \varepsilon=\varepsilon_{\mathrm{s}}-\varepsilon_{\infty}\right)$, corresponding to dipolar relaxation are gathered in Table 2. We notice an increase of $\Delta \varepsilon$ after heating.

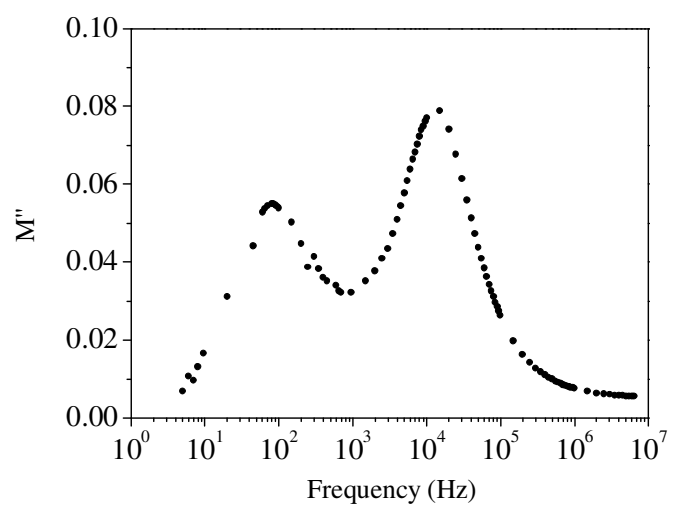

Fig. 9: Plot of M" versus frequency for un-heated sample

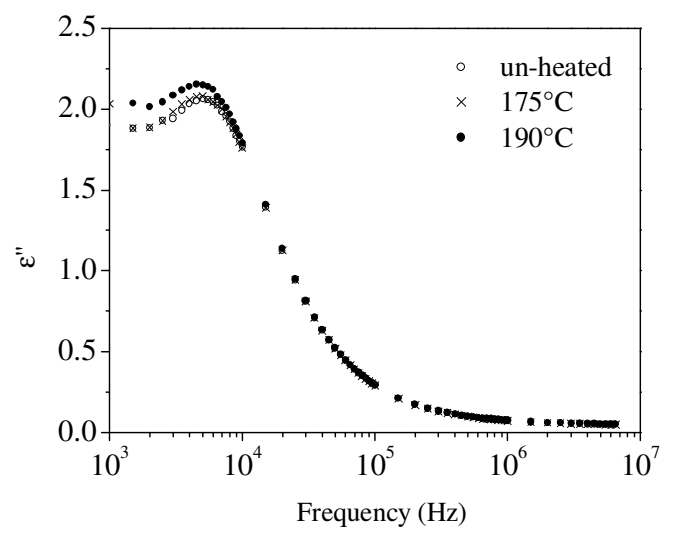

Fig. 10: Plots of $\varepsilon "$ versus frequency for un-heated and heated samples

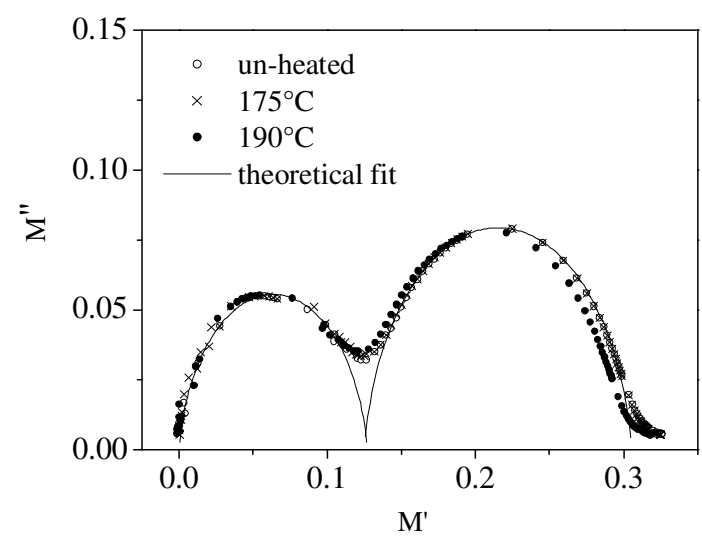

Fig. 11: Plots of $M^{\prime \prime}$ versus $M^{\prime}$ for un-heated and heated samples. Solid line is a cole-cole fit of un-heated sample 
Am. J. Engg. \& Applied Sci., 2 (1): 120-126, 2009

Table 2: Parameters of dipolar relaxation for un-heated and heated samples

\begin{tabular}{lllll}
\hline Sample & $\alpha$ & $\varepsilon_{\mathrm{s}}$ & $\varepsilon_{\infty}$ & $\Delta \varepsilon$ \\
\hline Un-heated & 0.0811 & 7.9936 & 3.2733 & 4.7203 \\
Heated at $175^{\circ} \mathrm{C}$ & 0.0882 & 8.0972 & 3.2744 & 4.8228 \\
Heated at $190^{\circ} \mathrm{C}$ & 0.0942 & 8.4246 & 3.3434 & 5.0812 \\
\hline
\end{tabular}

\section{DISCUSSION}

DSC results have shown that physical ageing appears in heated samples. Indeed, during heating chains being more mobile, rearrange themselves more easily into a more closely packed configuration reducing free volume. The structure of the heated PEI, being more stable, the material absorbs more energy (at the glass transition) to achieve the rubber state. A higher degree of physical ageing was observed for the heating temperature of $190^{\circ} \mathrm{C}$.

The reduction of free volume due to heating decreases the molecular mobility, consequently band intensities of the infrared spectra are affected. The disappearance of the absorption band at $2850 \mathrm{~cm}^{-1}$ assigned to $\mathrm{C}-\mathrm{H}$ vibration can be also explained by the reduction of molecular mobility.

We have found that the amount of dipoles relaxing during TSDC measurements is more important in sample heated at $175^{\circ} \mathrm{C}$. A possible explanation is the creation of dipoles and/or charges by heating as shown for other materials ${ }^{[15-17]}$. A decrease of the relaxation peak areas is observed after heating at $190^{\circ} \mathrm{C}$. The structural unities of molecular chains are more entangled due to the decrease of free volume, which increases dipolar interactions. Dipoles are in low energy levels, as a result, the amount of dipoles relaxing during TSDC measurements decreases.

The decrease of dipolar relaxation frequency when PEI is heated at $190^{\circ} \mathrm{C}$, is associated with an increase of dipolar interactions, which reduces dipoles mobility. This is related to physical ageing phenomenon. On the other hand, the increase of relaxation strength upon thermal conditioning can be related to an increase of the dipoles density because of the volume shrinkage.

\section{CONCLUSION}

Heating effects on both structural and electrical properties of polyetherimide have been studied by using different complementary techniques. It was found that heating favours physical ageing. Three electrical mechanisms were revealed in PEI: interfacial relaxation, dipolar relaxation and conduction. The dipolar relaxation is the most sensitive process to heat effect. It was shown that charge interactions increase due to physical ageing. Thus, heating leads to a decrease of dipoles mobility and stabilizes charges in deeper energetic levels.

\section{ACKNOWLEDGMENT}

The researchers acknowledge $\mathrm{Mr} \mathrm{H}$. Ben Ouada (Laboratoire de Physique et Chimie des Interfaces, F.S.M., Tunisia), the financial support of the 'Ministère de l'enseignement supérieur, de la recherche scientifique et de la technologie', Tunisia and ICTP through TWAS Grant no. 00-043 RG/PHYS/AF/.

\section{REFERENCES}

1. Truong, V.H., 1999. Study of the dielectric breakdown and the space charge in solid insulator (polyetherimide) under electrical, thermal and mechanical combination effects. Thesis, University Paul Sabatier.

http://cat.inist.fr/?aModele=afficheN\&cpsidt=197279

2. Krause, E., G.M. Yang and G.M. Sessler, 1998. Charge dynamics and morphology of Ultem 1000 and Ultem 5000 PEI grade films. Polym. Int., 46: 59-64. http://cat.inist.fr/?aModele=afficheN\&cpsidt=2261030

3. Mudarra, M., J. Belana, J.C. Cañadas, J.A. Diego and J. Sellarès, 2000. Space charge relaxation in polyetherimides by the electric modulus formalism. J. Applied Phys., 88: 4807-4812. DOI: 10.1063/1.1312839

4. Sanchis, M.J., R. Díaz-Calleja, C. Jaïmes, J. Belana, J.C. Cañadas, J.A. Diego, M. Mudarra and J. Sellarès, 2004. A relaxational and conductive study on two poly(ether imide)s. Polym. Int., 53: 1368-1377. DOI: 10.1002/pi. 1544

5. Belana, J., J.C. Cañadas, J.A. Diego, M. Mudarra, R. Díaz-Calleja, S. Friederichs, C. Jaïmes and M.J. Sanchis, 1998. Comparative study of mechanical and electrical relaxations in poly(etherimide) Part 1. Polym. Int., 46: 11-19. http://cat.inist.fr/?aModele=afficheN\&cpsidt=2261225

6. Zebouchi, N., V.H. Truong, R. Essolbi, M. Se-Ondoua, D. Malec, N. Vella, S. Malrieu, A. Toureille, F. Schué and R.G. Jones, 1998. The electric breakdown behaviour of polyetherimide films. Polym. Int., 46: 54-58. http://www3.interscience.wiley.com/journal/5260/abstra ct?CRETRY $=1 \&$ SRETRY $=0$

7. Smaoui, H., N. Mzabi, H. Guermazi, Y. Mlik, S. Agnel, A. Toureille and F. Schué, 2007. Characterisation of gamma-irradiated polyetherimide films with infrared spectroscopy and thermally stimulated current measurements. Polym. Int., 56: 325-332. DOI: $10.1002 /$ pi.2135 
8. Belana, J., J.C. Cañadas, J.A. Diego, M. Mudarra, R. Díaz, S. Friederichs, C. Jaimes and M.J. Sanchis, 1998. Physical ageing studies in polyetherimide ULTEM 1000. Polym. Int., 46: 29-32. http://cat.inist.fr/?aModele $=$ afficheN\&cpsidt $=2260970$

9. Echeverria, I., P.C. Sun, S.L. Simon and D.J. Plazek, 1995. Physical aging of a polyetherimide: Creep and DSC measurements. J. Polym. Sci. B. Polym. Phys., 33: 2457-2468. http://direct.bl.uk/bld/PlaceOrder.do?UIN=000251 203\&ETOC $=$ RN\&from $=$ searchengine

10. Brinke, G.T. and R. Grooten, 1989. Enthalpy relaxations in polymer blends and block copolymers: Influence of domain size*. Colloid Polym. Sci., 267: 992-1001. DOI: 10.1007/BF01410160

11. Qariouh, H., N. Raklaoui, R. Schué, F. Schué and C. Bailly, 1999. Electrophoretic deposition of polyetherimide from an aqueous emulsion: Optimisation of some deposition parameters. Polym. Int., 48: 1183-1192. http://direct.bl.uk/bld/PlaceOrder.do?UIN=070594 419\&ETOC $=$ RN\& from $=$ searchengine

12. Pavia, D.L., G.M. Lampman and G.S. Kriz, 1979. Introduction to Spectroscopy: A Guide for Students of Organic Chemistry. Saunders, Philadelphia, ISBN: 0721671195, pp: 367.

13. Silverstein, R.M., G.C. Bassler and T.C. Morrill, 1991. Spectrometric Identifications of Organic Compounds. John Wiley and Sons, Inc., ISBN: 0471634042, pp: 430.
14. Lin-Vien, D., N.B. Colthup, W.G. Fateley and J.G. Grasselli, 1991. The Handbook of Infrared and Raman Characteristic Frequencies of Organic Molecules. Harcourt Brace Jovanovich Publishers, London, ISBN: 0124511600, pp: 503.

15. Guermazi, H., H. Smaoui, S. Agnel, Y. Mlik, A. Toureille and F. Schué, 2001. Influence of heat treatment on the space charge within an epoxy resin polymer material. Polym. Int., 50: 743-747. DOI: $10.1002 /$ pi.695

16. Smaoui, H., H. Guermazi, S. Agnel, Y. Mlik, A. Toureille and F. Schué, 2003. Structural changes in epoxy Resin Polymer after heating and their influence on space charges. Polym. Int., 52: 1287-1293. DOI: 10.1002/pi.1217

17. Medhioub, H., H. Smaoui, N. Fourati, C. Zerrouki, H. Guermazi and J.J. Bonnet, 2008. Heat treatment effects on dielectric and physico-chemical properties of an epoxy polymer. J. Phys. Chem. Solids, 69 : 2476-2480. DOI: 10.1016/j.jpcs.2008.05.002

18. Tsangaris, G.M., G.C. Psarras and N. Kouloumbi, 1998. Electric modulus and interfacial polarization in composite polymeric systems. J. Mater. Sci., 33: 2027-2037. DOI: 10.1023/A: 1004398514901 